\title{
Influence of daylength on vernalization of winter rye
}

\author{
TH. A. HARTMAN \\ Instituut voor Biologisch en Scheikundig Onderzoek van Landbouwgewassen (I.B.S.), \\ Wageningen, Netherlands
}

\begin{abstract}
Summary
Winter cereals require a cold period to enable the plants to reach the stage of flowering and ear production in the next period of optimal daylength and temperature. In latitudes where winter cereals are grown this is duly taken into account to enable the germinating seed and seedlings to remain at low temperatures for the desired period. When these cereals are sown in spring they may perhaps differentiate flower primordia, be it with much delay, but generally no ears are formed. Many early attempts have been made to meet this cold requirement artificially, while more recently the influence of daylength has also been included in this research.
\end{abstract}

\section{Introduction}

MCKinNey (1940), also quoted by Whyte (1948) and ThOMPson (1953), refers to a report by KLIPPART from 1857, dealing with the results of winter wheat sown in spring after a pre-treatment at low temperatures. KLIPPART stressed herein the importance of using germinating seed, hampered in growth by low temperatures, until it was sown in spring so that, in fact, he recorded the principle of seed vernalization for the first time.

KURTH (1955) mentioned vON SEELHORST's experiments in 1898, those of APPEL and GASSNER in 1907, and FrüHWTRT's experiments in 1907. VoN SeElHORST placed germinating seed of winter rye, winter barley and winter wheat at $2-5^{\circ} \mathrm{C}$ during $2-4$ weeks, resulting in a maturation of the plants in the year of sowing. APPEL and GASSNER, and FRÜHWIRT, investigated the influence of temperature during germination on the further development of cereals.

GASSNER (1918), also mentioned by WHYTE (1948) and KURTH (1955), observed that winter cereals require a cold period specific for each species, i.e. each species needs a different treatment at temperatures of around $0^{\circ} \mathrm{C}$ to initiate flower primordia. An other investigation in which summer and winter rye were sown at $1-2^{\circ}, 5-6^{\circ}$, $12^{\circ}$ and $24^{\circ} \mathrm{C}$ showed that summer rye will shoot without a preliminary cold period, while winter rye required a certain period at low temperatures either during germination or in a later stage.

PURvis (1934) found by microscopic examination of the growing point during growth that differentiation of flower primordia is not only influenced by temperature during germination, but also by daylength in the period following cold treatment. These factors determine the growth rate of the meristematic growing point as well as the

Received for publication 27th November, 1963. 
number of leaf primordia preceding floral initiation. Under the most favourable conditions the plant produces a minimum of seven leaves, while a maximum of 25 is reached under unfavourable conditions.

Purvis concluded from this that the first seven primordia will always develop into leaves (stable primordia), from the 8th onward into a leaf or a flower (labile primordia) according to conditions and after the 25 th always into a flower. As the vegetative phase is terminated by the initiation of flower primordia, PuRvis and coworkers (GREGORY, 1937 and 1948; GorT, 1955) assumed that the leaf number is a standard for the relative rate of vegetative growth. This assumption is also mentioned by Van DE SANDE BaKhUYZen (1947), WhYTe (1948), LANG (1952) and HäNsel (1953).

In experiments with summer and winter wheat McKINNEY and SANDo (1935) also found that temperatures and photoperiods, stimulating early ripening, resulted in a reduced number of leaves and internodes on the main stem in winter wheat.

Maximov and Pojarkova (1925) observed that vernalized and non-vernalized winter wheat will shoot at approximately the same time after wintering in the greenhouse. In view of this they assume that short day during the winter months and cold treatment have a similar effect on reproductive development. In a later research, however, MAXIMOv (1930) only put down a retarding effect of short-day treatment on shooting.

GREGORY and PURvis (1937) observed that flower primordia were sooner initiated in short day than in long day when the seed was germinated at $18^{\circ} \mathrm{C}$, but for further development the short-day treatment had to be followed by a long-day period. In non-vernalized winter rye a short-day period of 6 weeks after sowing, followed by long day, resulted in an acceleration which is expressed, amongst others, by a reduction in leaf number from 25 to 16 . If, however, short-day treatment was continued plant development was retarded.

Floral initiation accordingly may be advanced by a cold treatment as well as by a preliminary short-day treatment. The same reaction has been found by Voss (1939), DenfFer (1939) and van de SANDe BakhuYzen (1947) in winter barley and by Feekes (1941) in winter wheat.

Gregory and Purvis (1937) account for the reactions of germinating seed to cold and short-day treatment by assuming the production of a flower hormone, affecting the labile primordia with various effects according to prevailing conditions. The interrelations of various influences were represented as in the scheme below (also mentioned in van de Sande BakhuYzen, 1947; Melchers and Lang, 1948; Whyte, 1948; LANG, 1952; HäNSEL, 1953 and GoTT, 1955).

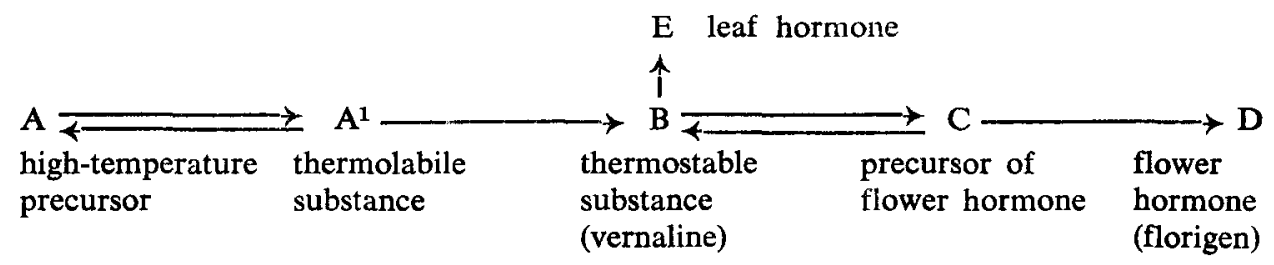

The substance $A$, present in the grain, is transformed via $A^{1}$ into the hormone-like substance $B$. The reaction can be accelerated by low temperatures. The substance $C$ is formed when $B$ has reached a certain concentration and this is stimulated by shortday treatment. Under favourable day-length conditions, i.e. long day, the substance $\mathrm{C}$ will be transformed into the flower hormone. When short-day treatment is continued 
after $\mathrm{C}$, the reaction $\mathrm{C} \rightarrow \mathrm{D}$ is blocked until a certain concentration is reached. After this the reaction will reverse and an equilibrium will be reached with $B$. An additional reaction $\mathrm{B} \rightarrow \mathrm{E}$ composes a leaf hormone $\mathrm{E}$.

VAN DE SANDE BAKHUYzen (1947) assumed the production of more hormone-like substances. The protocaline present in the grain is transformed into rhizocaline, phyllocaline, caulocaline and vernaline. The influence of the low temperature induces the formation of an enzyme in the grain, vernalase, which has a catalysing effect on the reaction protocaline $\rightarrow$ vernaline. He assumes an "interphase" between the "thermophase" and "photophase", in which short-day treatment has an accelerating effect on sub-optimally vernalized plants. During this phase vernaline is accumulated and after a certain value has been reached this leads to the formation of anthocaline (see also WiEBosch, 1950).

HäNSEL (1951) indicates the differences between plants after a cold period and those after a short-day treatment with regard to the leaf and flower primordia in the growing cone. After an optimal cold treatment the flowering stage may be reached without an increase in primordia. If plants are kept at optimal temperatures and daylength (long day) conditions after the cold period, only seven leaf primordia will be initiated and the number of spikelets per ear will remain low as well. Under shortday conditions, however, the rate of growth of the growing point is larger than under long-day conditions and many (twenty five) leaf primordia are initiated. If short day is followed by a long-day treatment, a part of the labile primordia will change into flower primordia and thus a relatively great number of spikelets per ear are produced.

RAZUMOV and OleINIKOWA (1960) made short-day vernalization dependent on temperatures. At high temperatures no vernalization takes place and daylength will not have any effect on the development of winter cereals. If, however, cold treatment has not been optimal for a rapid vernalization, with regard to temperature and/or duration, the development of winter cereals may be accelerated by the effect of short day. Evans (1960), studying Lolium species and Poa pratensis, observed that in continuous day as well as in short day (8 hours) temperatures up to at least $10^{\circ} \mathrm{C}$ still resulted in complete vernalization. At higher temperatures vernalization was incomplete. With a photoperiod of 16 hours, however, a temperature of $7^{\circ} \mathrm{C}$ did not appear to be sufficient for complete vernalization. The possibility of vernalizing at higher temperatures in short day was due to the effect of cold-vernalization completed by that of short-day induction. The fact that there were no inhibitive reactions during a nyctoperiod, explained also that higher vernalization temperatures could be used in continuous day. Contrary to PuRvis and Gregory's observation that the vernalization effect was considerably decreased by subjecting the plants to short periods of $20^{\circ} \mathrm{C}$ during the cold treatment, Evans found that for Lolium perenne, which has a much larger cold requirement, this evidently was a most effective cold treatment, provided the high temperatures were applied during the day ( 8 hours) followed by $16 \mathrm{hrs}$ at $7^{\circ} \mathrm{C}$. He also explained this by the fact that the $20^{\circ} \mathrm{C}$ were applied during the photoperiod and accordingly without the inhibitive effect of the nyctoperiod.

\section{Statement of the problem}

Differentiation of the flower primordia may be considered as the most fundamental in the life cycle of a plant. At this stage the vegetative phase changes into the reproductive phase and the number of leaf primordia preceding this may be taken as a standard of the relative rate of the vegetative growth. 
Purvis observed that this differentiation is influenced by low temperature as well as by short day. The effect of low temperature is localised in the apical meristem, while the photoperiodic reaction is dependent on the presence of leaves.

The question arises how to consider the reactions of cold and short-day treatment with regard to each other.

In the hypothesis of PURVIS and GREgory both are part of one process, in which each factor affects the production of a hormone-like substance. The scheme shows that the effect of short-day treatment has been placed after that of cold treatment. In VAN DE SANDE BAKHUYZEN's scheme the effect of the low temperature (formation of vernalase) also precedes that of short day.

These hypotheses lead to the generally accepted conclusion that short-day treatment has an accelerating effect only if it is preceded by sub-optimal vernalization.

However, Purvis and Gregory also found evidence that flower primordia are sooner initiated in short day than in long day after the germination at $18^{\circ} \mathrm{C}$. Moreover, a short-day period of 6 weeks after sowing followed by long day also affected an acceleration in non-vernalized winter rye, evident from a reduction in leaf number from 25 to 16 . Both observations accordingly prove that plants may be advanced by short-day treatment without preceding vernalization.

In view of the above it seemed appropriate to investigate whether the effects of low temperature and short day should not be considered as two completely independent reactions which may act simultaneously under conditions when cold as well as short day are active (plant vernalization).

Such an investigation calls for experiments in which the effect of a short-day treatment before, during and after vernalization can be determined separately. This requires cold treatments of young plants and control of daylength and temperature.

One of the greenhouse compartments at the I.B.S. meets these experimental demands. It has an automatic heating system and is also provided with an automatic mechanical cooling, so that an almost constant temperature can be maintained by day and night during the whole winter period. Vernalization has been carried out at $+6^{\circ} \mathrm{C}$ as earlier investigations (HARTMAN, 1956) showed an optimal vernalization effect at this temperature.

\section{Material and methods}

Petkuser winter rye was used in the investigation, carried out during 1958-1961. In the first three years the short-day treatments before, during and after vernalization consisted of natural winter daylength, and in 1961 of an 8-hour day obtained by covering the plants. The experiments were carried out with young plants (I), seedlings (II) and germinating seed (III) in pots :

I : Cold treatments of $14,28,42$ and 56 days (vernalization classes) at $6^{\circ} \mathrm{C}$ were applied to plants of 10-14 days old. In 1961 treatments for 70 and 84 days were added. The plants had been raised at $16^{\circ} \mathrm{C}$ and had formed $2-3$ leaves. In the 1958 and 1959 experiments the plants grew in natural day $\left(\mathrm{N}_{16}\right)$ during this period (= pre-treatment). In 1960 and 1961, however, half of each vernalization class received pre-treatment in continuous day $\left(C_{16}\right)$, the remaining part in $N_{16}$ (in 1961 short day $=S_{16}$ ). In the cold treatment each group was again divided into two parts, which were put in continuous day $\left(\mathrm{C}_{6}\right)$ and in natural day $\left(\mathrm{N}_{6}\right)$, in 1961 in short day $\left(\mathrm{S}_{6}\right)$. The post-treatment was the same for all treatments, viz. $16^{\circ} \mathrm{C}$ in continuous day while the sowing dates of the various vernalization classes had been chosen in such a way that for all plants post-treatment started at the same time. 
Thus the following combinations were obtained:

$\ldots \mathrm{C}_{16} \ldots \mathrm{C}_{6} \ldots \mathrm{C}_{16} ; \ldots \mathrm{C}_{16} \ldots \mathrm{N}_{6} \ldots \mathrm{C}_{16} ; \ldots \mathrm{N}_{16} \ldots \mathrm{C}_{6} \ldots \mathrm{C}_{16}$ and $\ldots \mathrm{N}_{16} \ldots \mathrm{N}_{6} \ldots \mathrm{C}_{16}$.

II : After sowing the pots remained at $16^{\circ} \mathrm{C}$ until the seedlings had emerged to about $1 / 2 \mathrm{~cm}$ above the soil, in 1959 in natural day $\left(\mathrm{N}_{16}\right)$, in 1960, however, in continuous day $\left(\mathrm{C}_{16}\right)$ to prevent any possible influence of natural day on the seedlings. During the cold treatments of $14,28,42$ and 56 days half of each vernalization class was put in continuous day, the remaining part in natural day. All treatments were entered into the post-treatment at the same time by chosing the various sowing dates accordingly. The various continuous-day and natural-day treatments were divided into subgroups which received continuous day after natural-day intervals of $0,7,14,21$ and 28 days, and natural day only.

III: After pre-germination at room temperature (ca. $18^{\circ} \mathrm{C}$ ) the seeds were placed in a refrigerator at $+6^{\circ} \mathrm{C}$ with a fluctuation of $+1 / 2^{\circ}$ and $-1 / 2^{\circ} \mathrm{C}$ during $14,28,42$ and 56 days. The vernalization classes were started in such a way that all treatments could be planted in a greenhouse at $16^{\circ} \mathrm{C}$ at the same time, each vernalization class being divided into groups placed in continuous day, natural day and continuous day preceded by natural-day periods of $7,14,21$ and 28 days (investigation 1960).

As a standard for acceleration/retardation the number of days was determined from the beginning of the post-treatment until the emergence of the ear from the leaf sheat (stage 10,1 according to FeEKEs, 1941). Strictly speaking, only treatments within one vernalization class should be compared, as comparisons between vernalization classes are affected by differences in sowing date.

Continuous day was obtained with the use of $25 \mathrm{~W}$ incandescent bulbs at night (1 per $\left.11 / 2 \mathrm{~m}^{2}\right)$ in $1958,40 \mathrm{~W}$ fluorescent tubes $\left(1\right.$ per $\left.11 / 2 \mathrm{~m}^{2}\right)$ being used in other years because of a more favourable light distribution. The great influence of the kind of light used became apparent, as in 1958 additional light considerably increased leaf size, while in the other years this effect was much smaller. This may be explained by a larger formative effect of incandescent light in comparison to fluorescent tubes.

In the investigation of 1961 the treatments were periodically sampled. These samples were analysed for fresh and dry weight, while the development stage of the growing points was expressed in WITTENROon's scale of development stages (1953), indicating development until the ears have been formed (see below).

DEVElOPMENTAL STAGES IN WINTER RYE ACCORDING TO WITTENROOD

Vegetative stage

Valuation

1a : youngest stage

$1 b$ : the youngest primordia are bract-like, semi-embracing the growing cone

Reproductive stage

$2^{\prime \prime \prime}$ : first swelling of the interbracteal spaces

$2^{\prime \prime}$ : the first interbracteal space swollen

$2^{\prime}$ : more swollen interbracteal spaces, but the bracts project beyond the swelling

2 : the swollen interbracteal spaces (= ear primordia) are as large as the bracts, but are still smooth ("double ridge" stage of PuRvis and GREGORY) 
3 : differentiation of glumes $\quad 3,0$

4 : differentiation of the primordium of 1st flower 4,0

5 : differentiation of the primordium of 2 nd flower $\quad 5,0$

6 : initiation of stamen in the 1st flower $\quad 6,0$

7 : initiation of stamen in the 2nd flower $\quad 7,0$

8 : differentiation of $3 \mathrm{rd}$ and 4th flower $\quad \mathbf{8 , 0}$

9 : 3rd and 4th flower clearly visible $\quad 9,0$

10 : development of glumes; the stamen are half covered 10,0

11 : glumes fully grown; stamen completely covered 11,0

12 : development of awns 12,0

13 : awns fully grown 13,0

\section{The investigation}

4.1. Informative investigation in 1958 and 1959

Cold treatments were applied to older plants $(11-14$ days) in both years, in 1959 also to seedlings (5-7 days). The results are given in TABLE 1 . In this table, the coding of the treatments in the subsequent periods (pre-treatment at $16^{\circ} \mathrm{C} /$ cold treatment at $6^{\circ} \mathrm{C} /$ post-treatment at $16^{\circ} \mathrm{C}$ ) indicates the number of days and daylength conditions, viz. natural day $=\mathrm{N}$ and continuous day $=\mathrm{C}$. In the post-treatment period the number of days reflects the time until ear emergence. Incandescent bulbs were used in 1958 and fluorescent tubes in 1959 for additional illumination.

TABLE 1. Cold and natural-day treatments with older plants and seedlings

\begin{tabular}{|c|c|}
\hline \multicolumn{2}{|c|}{ Treatments } \\
\hline 1958 & 1959 \\
\hline $\begin{array}{lll}0 / 67 & C_{6} / 37 & C_{16} \\
0 / 67 & N_{6} / 50 & C_{16}\end{array}$ & $\begin{array}{lll}0 / 70 & C_{6} / 44 & C_{16} \\
0 / 70 & N_{6} / 50 & C_{16}\end{array}$ \\
\hline 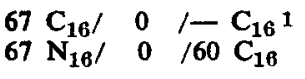 & $\begin{array}{lllll}70 & \mathrm{C}_{16} / & 0 & / 66 & \mathrm{C}_{16} \\
70 & \mathrm{~N}_{16} / & 0 & / 82 & \mathbf{N}_{16}\end{array}$ \\
\hline $\begin{array}{llll}11 & N_{16} / 56 & C_{6} / 35 & C_{16} \\
11 & N_{16} / 56 & N_{6} / 44 & C_{16}\end{array}$ & $\begin{array}{rlll}14 & N_{16} / 56 & C_{6} / 41 & C_{16} \\
14 & N_{16} / 56 & N_{6} / 44 & C_{16} \\
5 & N_{16} / 56 & C_{6} / 45 & C_{16} \\
5 & N_{16} / 56 & N_{6} / 46 & C_{16}\end{array}$ \\
\hline $\begin{array}{llll}11 & N_{16} / 42 & C_{6} / 40 & C_{16} \\
11 & N_{16} / 42 & N_{6} / 49 & C_{16}\end{array}$ & $\begin{array}{rlll}14 & N_{16} / 42 & C_{6} / 47 & C_{16} \\
14 & N_{16} / 42 & N_{6} / 52 & C_{16} \\
6 & N_{16} / 42 & C_{6} / 55 & C_{16} \\
6 & N_{16} / 42 & N_{6} / 54 & C_{16}\end{array}$ \\
\hline $\begin{array}{llll}11 & N_{16} / 28 & C_{6} / 57 & C_{16} \\
11 & N_{16} / 28 & N_{6} / 62 & C_{16}\end{array}$ & $\begin{array}{rlll}14 & \mathrm{~N}_{16} / 28 & \mathrm{C}_{6} / 59 & \mathrm{C}_{16} \\
14 & \mathrm{~N}_{16} / 28 & \mathrm{~N}_{6} / 55 & \mathrm{C}_{16} \\
7 & \mathrm{~N}_{16} / 28 & \mathrm{C}_{6} / 65 & \mathrm{C}_{16} \\
7 & \mathrm{~N}_{16} / 28 & \mathrm{~N}_{6} / 64 & \mathrm{C}_{16}\end{array}$ \\
\hline $\begin{array}{l}11 N_{16} / 14 C_{6} /-C_{16}{ }^{1} \\
11 N_{16} / 14 N_{6} /-C_{16}^{1}\end{array}$ & $\begin{array}{rlll}15 & N_{16} / 14 & C_{6} / 69 & C_{16} \\
15 & N_{16} / 14 & N_{6} / 73 & C_{16} \\
7 & N_{16} / 14 & C_{6} / 85 & C_{16} \\
7 & N_{16} / 14 & N_{6} / 89 & C_{16}\end{array}$ \\
\hline
\end{tabular}

1 No ear formation in observation period.

2 Erroneously placed in natural day. 


\subsection{Investigation in 1960}

Cold treatments were applied to 2-week-old plants (I), seedlings (II) and germinating seed (III). For additional illumination fluorescent tubes have been used:

I. In TABLE 2 the treatments have been arranged so as to allow the effect of the natural-day period in pre-treatment and during vernalization to be determined separately as well as combined. All treatments have been placed in the post-treatment at $16^{\circ} \mathrm{C}$ and continuous day at the same time.

II. The effect of a natural-day period during vernalization and in post-treatment has been observed. In post-treatment continuous day has been preceded by naturalday periods of varying length (TABLE 3 ).

In TABLE 2 and 3 the coding of the treatments reflects the number of days and daylength conditions (continuous day $=\mathrm{C}$, natural day $=\mathrm{N}$ ) in pre-treatment at $16^{\circ} \mathrm{C} /$ cold treatment at $6^{\circ} \mathrm{C} /$ post-treatment at $16^{\circ} \mathrm{C}$. The number of days in the post-treatment indicates the time until heading (stage 10,1; FEEKES, 1941).

III. The influence of the natural-day intervals in post-treatment has also been observed in plants grown from seed which received cold treatment of varying length (seed vernalization). For the experimental design and results see tABLE 4 .

TABLE 2. Effects of natural day before and during cold periods of varying length with 2 -week old plants

\begin{tabular}{|c|c|c|c|}
\hline Treatments & & lumns & \\
\hline & $\begin{array}{c}1 \\
N_{16}\end{array}$ & $\stackrel{2}{\mathbf{N}_{6}}$ & $\begin{array}{c}3 \\
\text { total }\end{array}$ \\
\hline 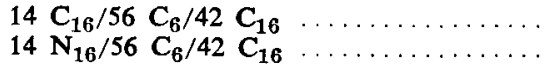 & 0 & & 0 \\
\hline 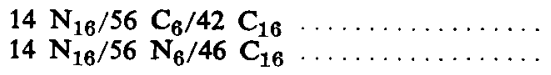 & & -4 & -4 \\
\hline 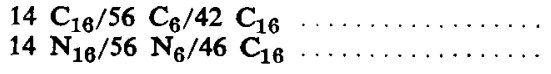 & 0 & -4 & -4 \\
\hline $\begin{array}{lllll}14 & C_{16} / 56 & C_{6} / 42 & C_{16} & \ldots\end{array} \ldots \ldots \ldots \ldots \ldots$ & & -2 & -2 \\
\hline  & +4 & & +4 \\
\hline 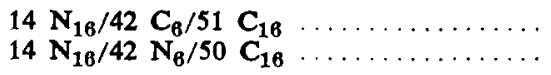 & & +1 & +1 \\
\hline 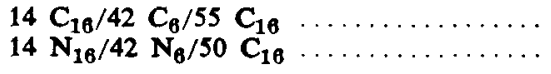 & +4 & +1 & +5 \\
\hline 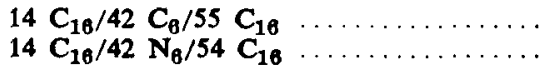 & & +1 & +1 \\
\hline 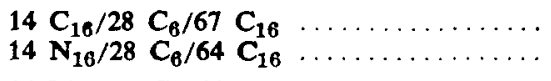 & +3 & & +3 \\
\hline 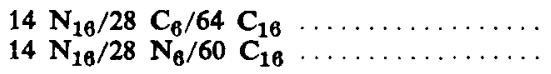 & & +4 & +4 \\
\hline $\begin{array}{lllll}14 & \mathbf{C}_{18} / 28 & \mathbf{C}_{8} / 67 & \mathbf{C}_{16} & \ldots\end{array} \ldots \ldots \ldots \ldots \ldots$ & +3 & +4 & +7 \\
\hline 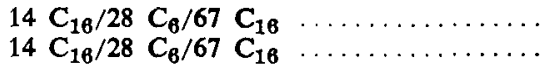 & & 0 & 0 \\
\hline
\end{tabular}




\begin{tabular}{|c|c|c|c|}
\hline \multirow[t]{2}{*}{ Treatments } & \multicolumn{3}{|c|}{ Columns } \\
\hline & $\begin{array}{c}1 \\
\mathrm{~N}_{16}\end{array}$ & $\stackrel{2}{\mathrm{~N}_{6}}$ & $\begin{array}{c}3 \\
\text { total }\end{array}$ \\
\hline 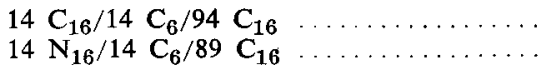 & +5 & & +5 \\
\hline 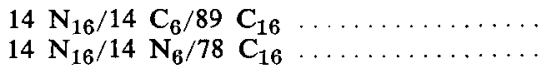 & & +11 & +11 \\
\hline 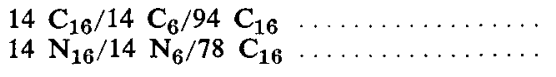 & +5 & +11 & +16 \\
\hline 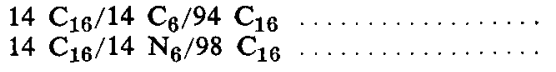 & & -4 & -4 \\
\hline
\end{tabular}

Column 1: acceleration $(+)$ or retardation $(-)$ of ear emergence caused by natural day in pretreatment $\left(\mathrm{N}_{16}\right)$; column 2 : ditto, caused by natural day during vernalization $\left(\mathrm{N}_{6}\right)$; column 3 : total acceleration/retardation.

TABLE 3. Effects of natural day during and after cold periods of varying length with seedlings

\begin{tabular}{|c|c|c|c|}
\hline Treatments & & blumns & \\
\hline  & $\begin{array}{c}1 \\
\mathbf{N}_{6}\end{array}$ & $\begin{array}{c}2 \\
\mathrm{~N}_{16} \\
+2 \\
-2 \\
-7 \\
-12 \\
-43\end{array}$ & $\begin{array}{c}3 \\
\text { total } \\
+2 \\
-2 \\
-7 \\
-12 \\
-43\end{array}$ \\
\hline  & $\begin{array}{l}+3 \\
+3 \\
+3 \\
+3 \\
+3 \\
+3\end{array}$ & $\begin{array}{l}-1 \\
-5 \\
-9 \\
-13 \\
-47\end{array}$ & $\begin{array}{l}+3 \\
+2 \\
-2 \\
-6 \\
-10 \\
-44\end{array}$ \\
\hline 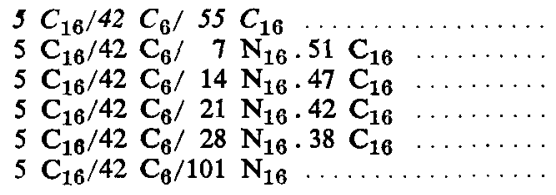 & & $\begin{array}{l}-3 \\
-6 \\
-8 \\
-11 \\
-46\end{array}$ & $\begin{array}{l}-3 \\
-6 \\
-8 \\
-11 \\
-46\end{array}$ \\
\hline 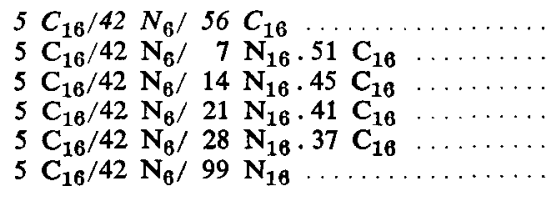 & $\begin{array}{l}-1 \\
-1 \\
-1 \\
-1 \\
-1 \\
-1\end{array}$ & $\begin{array}{l}-2 \\
-3 \\
-6 \\
-9 \\
-43\end{array}$ & $\begin{array}{l}-1 \\
=3 \\
-4 \\
-7 \\
-10 \\
-44\end{array}$ \\
\hline 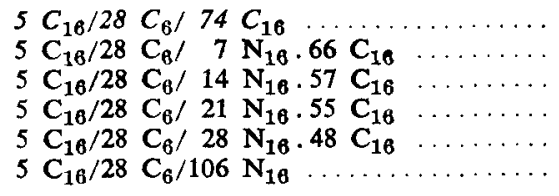 & & $\begin{array}{l}+1 \\
+3 \\
-2 \\
-2 \\
-32\end{array}$ & $\begin{array}{l}+1 \\
+3 \\
-2 \\
-2 \\
-32\end{array}$ \\
\hline 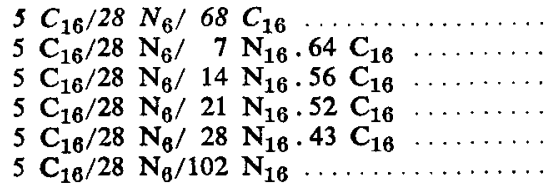 & $\begin{array}{l}+6 \\
+6 \\
+6 \\
+6 \\
+6 \\
+6\end{array}$ & $\begin{array}{l}-3 \\
-2 \\
-5 \\
-3 \\
-34\end{array}$ & $\begin{array}{l}+6 \\
+3 \\
+4 \\
+1 \\
+3 \\
-28\end{array}$ \\
\hline
\end{tabular}

Neth. J. agric. Sci., Vol. 12 (1964) No. 2 (May) 
TH. A. HARTMAN

\begin{tabular}{|c|c|c|c|}
\hline Treatments & & lumns & \\
\hline 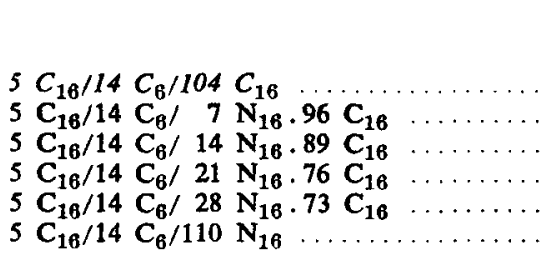 & $\begin{array}{c}1 \\
\mathrm{~N}_{6}\end{array}$ & $\begin{array}{r}2 \\
N_{16} \\
+1 \\
+1 \\
+7 \\
+3 \\
-6\end{array}$ & $\begin{array}{c}3 \\
\text { total } \\
+1 \\
+1 \\
+7 \\
+3 \\
-6\end{array}$ \\
\hline  & $\begin{array}{l}+2 \\
+2 \\
+2 \\
+2 \\
+2 \\
+2\end{array}$ & $\begin{array}{r}+1 \\
+3 \\
+8 \\
+10 \\
-5\end{array}$ & $\begin{array}{l}+2 \\
+3 \\
+5 \\
+10 \\
+12 \\
-3\end{array}$ \\
\hline
\end{tabular}

Column 1: acceleration $(+)$ or retardation $(-\rightarrow)$ caused by $N_{6}$ compared with $5 C_{16} / \ldots C_{6} / \ldots C_{16}$; column 2: ditto, caused by $\mathrm{N}_{16}$ compared with $5 \mathrm{C}_{16} / \ldots \mathrm{C}_{6} / \ldots \mathrm{C}_{16}$ and $5 \mathrm{C}_{16} / \ldots \mathrm{N}_{6} / \ldots \mathrm{C}_{16}$ respectively; column 3: total acceleration/retardation compared with $5 \mathrm{C}_{16} / \ldots \mathrm{C}_{6} / \ldots \mathrm{C}_{\mathbf{1 6}}$.

TABle 4. Seed vernalization at $6^{\circ} \mathrm{C}\left(\mathrm{Sv}_{6}\right)$ with cold treatments of varying length

\begin{tabular}{|c|c|}
\hline Treatments & Effect of $\mathbf{N}_{18}$ \\
\hline 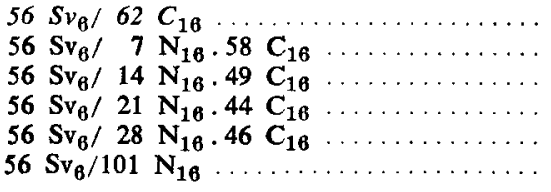 & $\begin{array}{r}-3 \\
-1 \\
-3 \\
-12 \\
-39\end{array}$ \\
\hline 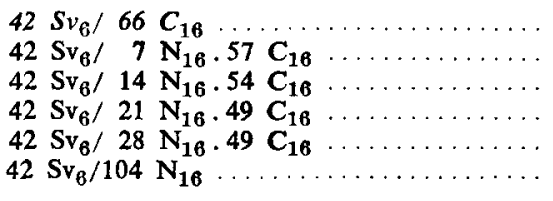 & $\begin{array}{r}+2 \\
-2 \\
-4 \\
-11 \\
-38\end{array}$ \\
\hline 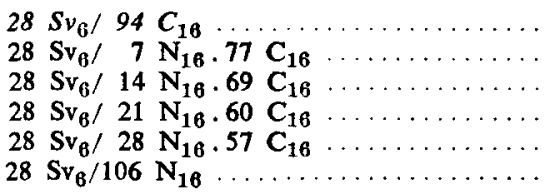 & $\begin{array}{r}+10 \\
+11 \\
+13 \\
+9 \\
-12\end{array}$ \\
\hline  & $\begin{array}{r}+2 \\
+2 \\
+7 \\
+10 \\
+4\end{array}$ \\
\hline
\end{tabular}

Note: The vernalized seeds were planted at $16^{\circ} \mathrm{C}$ in continuous day $\left(\mathrm{C}_{16}\right)$ with various natural-day intervals $\left(\mathrm{N}_{16}\right)$. The number of days in the post-treatment indicates the time until ear emergence (Feekes, stage 10,1$)$ in which the acceleration $(+)$ or retardation $(-)$ by the natural-day intervals has been expressed.

\subsection{Investigation in 1961}

Cold treatments at $6^{\circ} \mathrm{C}$ were applied to 2-week-old plants for $84,70,56,42,28$, 14 and 0 days. The sowing dates of the various vernalization classes were adjusted, so that all treatments came into the post-treatment at the same time. Conditions in 
the post-treatment were the same for all treatments (continuous day at $16^{\circ} \mathrm{C}$ ). In pretreatment and during vernalization, however, two daylength periods were applied, viz. continuous day (C) and a short day of 8 hours (S). Thus the following combinations have been obtained: $\ldots \mathrm{C}_{16} / \ldots \mathrm{C}_{6} / \ldots \mathrm{C}_{16} ; \ldots \mathrm{C}_{16} / \ldots \mathrm{S}_{6} / \ldots \mathrm{C}_{16} ; \ldots \mathrm{S}_{16} / \ldots \mathrm{C}_{8} / \ldots \mathrm{C}_{16}$ and $\ldots S_{16} / \ldots S_{6} / \ldots C_{16}$.

Fluorescent tubes were used for additional illumination, but in the vernalization class of 8 weeks a few treatments with additional illumination of incandescent bulbs were included. In these treatments the continuous day has been indicated by $L$.

In sampling, from the beginning of vernalization onwards till ear emergence, fresh and dry weight of the main stem and tillers were determined. The FIGUREs $1-8$ reflect the increase in dry weight of the main stem in the various treatments.

Microscopic analyses of the growing points in the vernalization classes with longer cold treatments $(84,70,56$ days) was started 10 days before the post-treatment commenced. Apparently, even at low temperature allowing slow growth, the plant may proceed from the vegetative phase into the reproductive phase. The progress of development has been reflected in FIG. 9-16.

\section{Discussion of the results}

\subsection{Results in 1958 and 1959}

In 1958 the difference in growth between the treatments with additional light and those without was considerably larger than in 1959. This is due to a larger formative effect on plant growth of the incandescent light. It may also explain why the difference in heading time between the continuous- and natural-day treatments of the various vernalization classes in 1958 were greater than those in 1959 , for instance



Apparently, there is a close correlation between increased growth rate and earlier heading. As the continuous-day treatments also show a more rapid growth than the natural-day treatments, they would have an advance in earliness. On the other hand, differentiation of flower primordia will take place more rapidly in natural day, as has been observed by PURvis and confirmed by own experiments. The relative earliness of the natural-day treatments is therefore determined by at least two components, the first being a reduced growth in comparison to continuous-day plants, the other an acceleration due to a more rapid differentiation of flower primordia. Thus, in the two comparisons

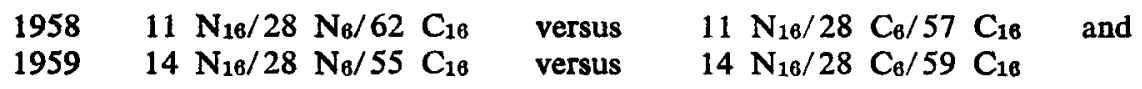

the growth component in 1958 was sufficient for the $\mathrm{C}_{6}$-treatment to be earlier than the $\mathrm{N}_{6}$-treatment, in spite of the speedier differentiation in the latter, while in 1959 it was not.

A comparison of the results obtained with older plants with those of the young seedlings reveals an interesting interaction of this comparison with the duration of the vernalization treatment. Thus in the 8 -week vernalization class the period between sowing and heading was significantly shorter for the seedlings than for the plants, 
TH. A. HARTMAN


Fig. 1

Growth curves in the 12-week vernalization class

FIg. 2

Growth curves in the 10 -week vernalization class 
the difference being 5 days for the continuous day and 7 days for the natural-day treatments. In the other vernalization classes of 6,4 and 2 weeks the corresponding differences are 0 and 6,1 and $-2,-8$ and -8 respectively. An explanation of this is to be found in the trend of plant growth. WiTTENRoon (1959) observed by length measurements in Peko, that, preceding visible shooting, plant growth progresses according to 2 curves (see FIG. hereunder).



Scheme of the growth of wheat grown in a greenhouse at a temperature of $18^{\circ} \mathrm{C}$ and with continuous light after growing in the open in winter; growth depressions at the end of the vegetative period and when there is no further increase in the number of spikelets (according to WitTENROOD (1959), FIG. 3)

It is evident from this FIG. that growth depressions occur at the end of the vegetative phase and in the period of ultimate spikelet number. These growth depressions are reflected in a flattening of the growth curves. In this investigation, in which 2 different temperatures $\left(6^{\circ} \mathrm{C}\right.$ in the vernalization period and $16^{\circ} \mathrm{C}$ in the post-treatment) are applied it is important when the end of the vegetative phase is reached. If this is the case during the cold treatment, when growth is already rather reduced by the low temperature $\left(6^{\circ} \mathrm{C}\right)$, the growth depression inherent to the end of the vegetative phase will give a considerable delay, which will be more pronounced when this stage falls earlier in the vernalization period. If the end of the vegetative phase is reached in the beginning of the post-treatment, however, the inherent growth depression will be more or less compensated by the increased growth due to higher temperature $\left(16^{\circ} \mathrm{C}\right)$. In the continuous-day treatments $14 \mathrm{~N}_{16} / 56 \mathrm{C}_{6} / 41 \mathrm{C}_{16}$ and $5 \mathrm{~N}_{16} / 56 \mathrm{C}_{6} / 45 \mathrm{C}_{16}$ the older plants reached this stage in the vernalization period, the seedlings, however, in the post-treatment, and thus the initial advantage of 9 days is reduced to 4 days. In the natural-day treatments $14 \mathrm{~N}_{16} / 56 \mathrm{~N}_{6} / 44 \mathrm{C}_{16}$ and $5 \mathrm{~N}_{16}$ / $56 \mathrm{~N}_{6} / 46 \mathrm{C}_{16}$ it was even reduced to 2 days. Apparently, the older plants in this treatment were even more retarded by growth depressions relative to the seedlings than in the continuous-day treatments.

This is reasonable, as owing to the more rapid differentiation of flower primordia in natural day, $14 \mathrm{~N}_{16} / 56 \mathrm{~N}_{8} / 44 \mathrm{C}_{16}$ may have reached the end of the vegetative phase earlier than in the continuous-day treatment. As a result the period of growth depressions during the cold treatment will have lasted longer. $14 \mathrm{~N}_{16} / 56 \mathrm{~N}_{6} / 44 \mathrm{C}_{16}$ has a delay of 3 days by $14 \mathrm{~N}_{16} / 56 \mathrm{C}_{6} / 41 \mathrm{C}_{16}$ which presumably consists of the natural-day effect (i.e. an acceleration due to more rapid differentiation of primordia and a retardation due to growth reduction) and a delay caused by a longer period of growth depression at the end of the vegetative phase. 

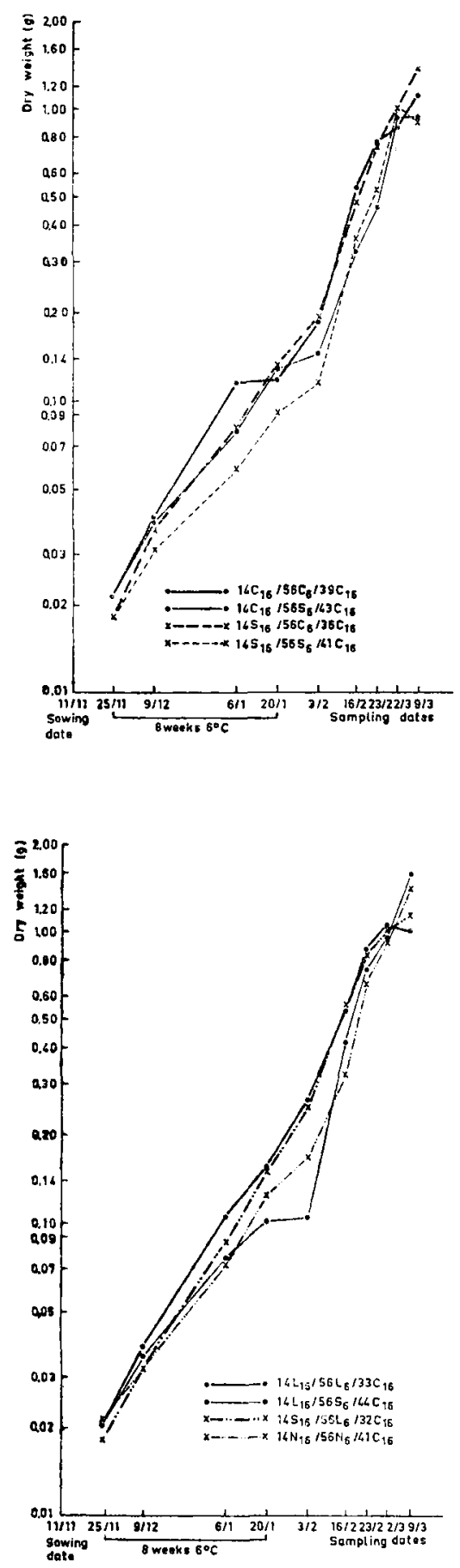

FIG. 3

Growth curves in the 8-week vernalization class with additional fluorescent illumination

FIG. 4

Growth curves in the 8-week vernalization class with additional incandescent illumination 

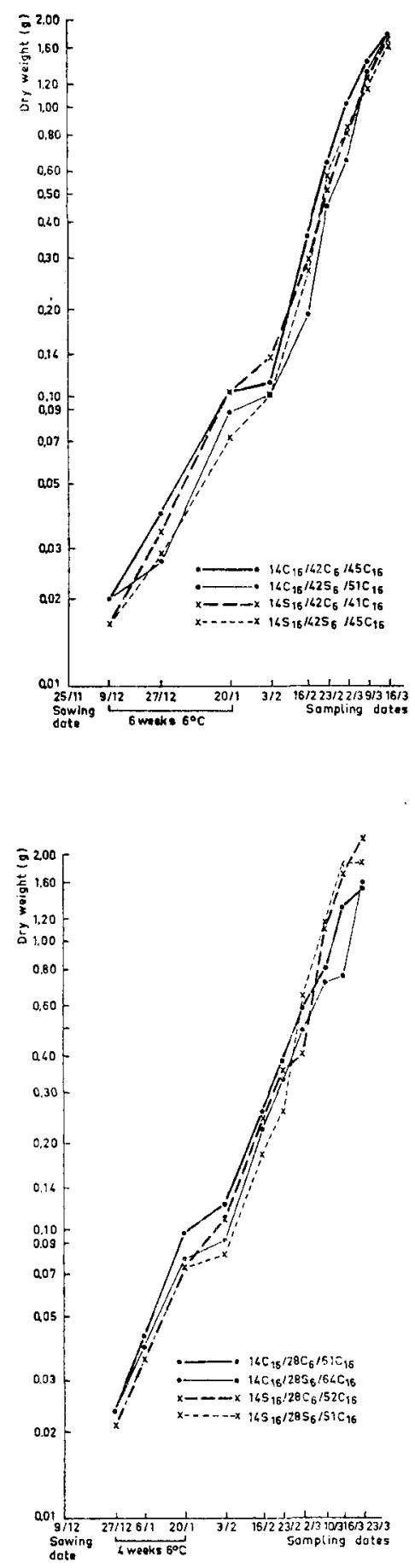

FIG. 5

Growth curves in the 6-week vernalization class
FIG. 6

Growth curves in the 4-week vernalization class 
In the 6-week vernalization class the difference in sowing dates is also revealed at ear emergence in the continuous-day treatments. This proves that both reach the end of the vegetative phase in the post-treatment. In the natural-day treatments, however, the older plants reach this stage already during the cold treatment, so that the inherent delay due to growth depression will reduce the advantage of 8 days to one of 2 days. The treatment $14 \mathrm{~N}_{16} / 42 \mathrm{~N}_{6} / 52 \mathrm{C}_{16}$ has a delay of 5 days as compared with $14 \mathrm{~N}_{16} / 42 \mathrm{C}_{6} / 47 \mathrm{C}_{16}$, which is the result of the same effect.

In the 2- and 4-week vernalization classes the continuous- as well as the naturalday treatments of older plants and seedlings probably reach this stage in the posttreatment, so that this kind of delay will be very small. Here the seedlings show a much longer period between sowing and heading in the 2-week vernalization class than the older plants. This must be attributed entirely to the greater number of short natural days these older plants received prior to vernalization. Thus the few indications from literature are confirmed that short day without preceding vernalization accelerates heading (p. 135).

PURvis and Gregory's observation that in non-vernalized winter rye natural day initially accelerates, whereas prolonged treatment will lead to retardation, can now be explained by the combined effect of two components. Besides a retardation by growth depression in short day there is also an acceleration due to a faster differentiation of the flower primordia. As the short-day treatment continues, both the retardation and the acceleration increase, but the latter at a higher rate until a maximum is reached. Thereafter continuation of the short-day treatment will not increase the acceleration, because there is still an increase in the value of the retardation.

\subsection{Results in 1960}

1. Experiments on young plants (TABLE 2)

In these series daylength in the pre-treatment has been varied as well as in the cold period, so that within each vernalization class the following treatments can be compared.

$$
\begin{array}{ll}
14 \mathrm{~N}_{16} / \ldots \mathrm{C}_{6} & 14 \mathrm{~N}_{16} / \ldots \mathrm{N}_{6} \\
14 \mathrm{C}_{16} / \ldots \mathrm{C}_{6} & 14 \mathrm{C}_{16} / \ldots \mathrm{N}_{6}
\end{array}
$$

In the 8-week vernalization class $14 \mathrm{~N}_{16} / 56 \mathrm{~N}_{6} / 46 \mathrm{C}_{16}$ is retarded 4 days as compared with $14 \mathrm{~N}_{16} / 56 \mathrm{C}_{6} / 42 \mathrm{C}_{16}$. This delay, as in the corresponding treatments in 1959 , is due to the fact that the end of the vegetative phase is reached earlier during the cold treatment. The treatments $14 \mathrm{C}_{16} / 56 \mathrm{C}_{6} / 42 \mathrm{C}_{18}$ and $14 \mathrm{~N}_{16} / 56 \mathrm{C}_{6} / 42 \mathrm{C}_{16}$ headed at the same time. In the previous comparison, however, it has been suggested that $14 \mathrm{~N}_{1.6} / 56 \mathrm{C}_{6} / 42 \mathrm{C}_{16}$ already reaches the end of the vegetative phase during vernalization. In fact, this treatment should actually show a delay as compared with $14 \mathrm{C}_{16} / 56 \mathrm{C}_{6} / 42 \mathrm{C}_{16}$, the latter reaching this stage later, possibly at the beginning, or else during the post-treatment. Hence the difference of 0 days indicates that the natural-day effect in the pre-treatment has resulted in an acceleration compensating the retardation. In $14 \mathrm{C}_{16} / 56 \mathrm{C}_{6} / 42 \mathrm{C}_{16}$ versus $14 \mathrm{C}_{16} / 56 \mathrm{~N}_{6} / 44 \mathrm{C}_{16}$ the natural-day treatment probably reaches the end of the vegetative phase in the post-treatment as well. Therefore no additional delay due to growth depression will occur and thus the difference of 2 days is entirely due to the natural-day effect.

In the 0-, 2-, 4- and 6-week vernalization classes the 14 days with natural daylength prior to vernalization resulted in early heading compared with 14-day pre-treatment in continuous light, as could be expected. 
FIG. 7. Growth curves in the 2week vernalization class

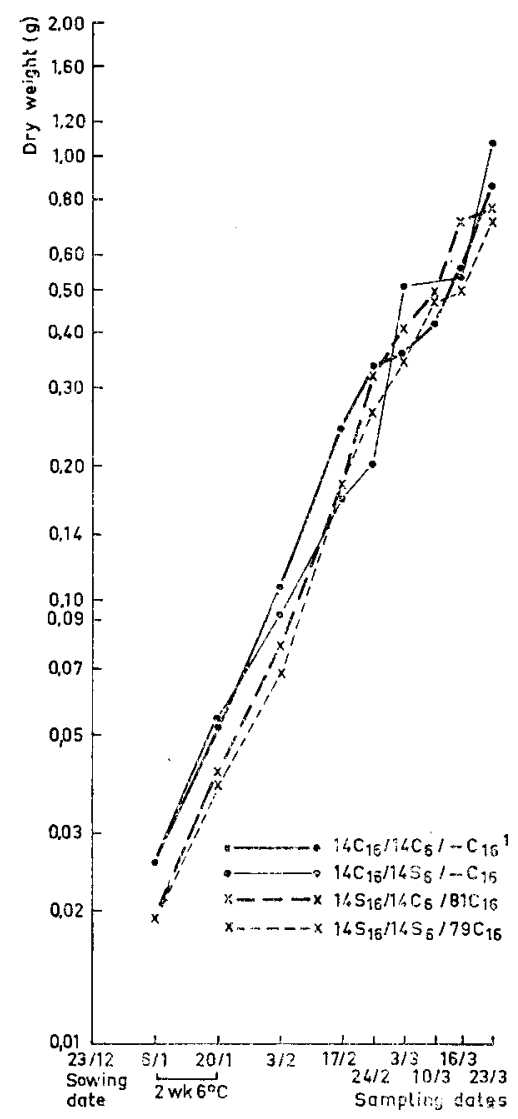

Fig. 8. Growth curves of unvernalized winter rye

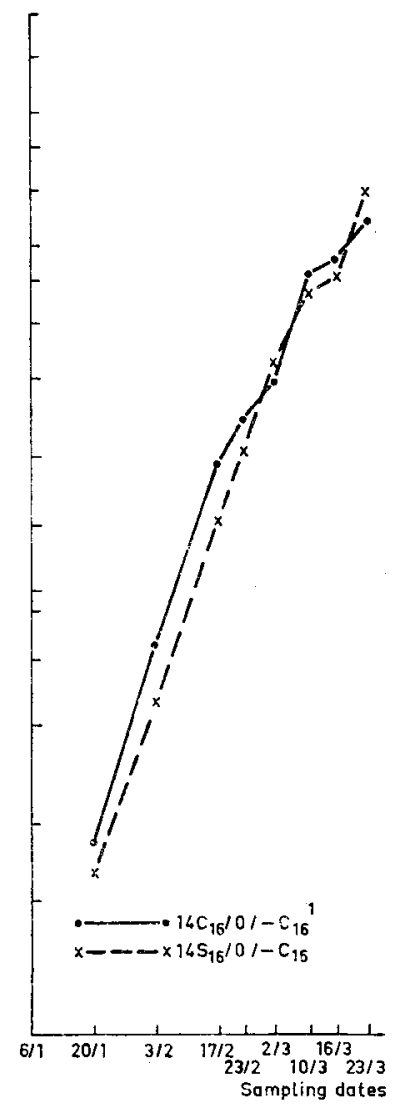

\section{Experiments on seedlings (TABLE 3)}

In each vernalization class there are two main treatments in the cold period, viz. continuous day $5 \mathrm{C}_{16} / \ldots \mathrm{C}_{6} / \ldots$ and natural day $5 \mathrm{C}_{16} / \ldots \mathrm{N}_{6} / \ldots$ Within each main treatment a number of sub-groups were formed with different natural-day intervals in the after-period. The effect of the natural day during the cold period may be assessed by comparing the main treatments and the effect of natural-day intervals after vernalization by comparing the treatments of each group with the concerning main treatment. In the natural-day group the final outcome of these results shows the ultimate acceleration/retardation relative to the continuous-day treatment.

The rate of heading in the continuous-day treatments in the first place will be determined by the influence of the low temperature (vernalization). If the cold requirement has not been met completely, the natural-day intervals in the post-treatment have an accelerating effect until the optimal earliness is attained, i.e. the minimum number of days this treatment needs till ear emergence. Hereafter natural-day condi- 
tions will give retardations, as the acceleration caused by more rapid differentiation of primordia cannot be expressed anymore and the result will then be influenced only by the retardation from growth depression.

The natural-day treatments are influenced by cold as well as by the natural-day effect. A comparison of the main treatments in the various vernalization classes shows that the combined effects of cold and natural day lead to a lower minimum of days to ear emergence. In the 6-week vernalization class only the acceleration due to the combined effect of cold and natural day is evidently smaller than the advantage resulting from a more rapid growth in continuous day.


Fig. 9

Development curves in the 12-week vernalization class

FIG. 10

Development curves in the 10-week vernalization class 
III. Experiments on germinating seed (TABLE 4)

In vernalizing germinating seeds it is obvious that the result will be primarily influenced by the effect of low temperature. This effect like that of natural day is two-fold. The low temperature depresses seedling growth, but at the same time changes take place, enabling later development to be more accelerated than that in plants of non-vernalized seed. If cold requirement has been completely met, the treatments will head most rapidly after planting in the most favourable daylength, i.e. continuous day. A natural-day period in the post-treatment will then only lead to retardation, because the minimal number of days till ear emergence has already been reached and accordingly the accelerating effect of natural day cannot be expressed anymore.

In the 8-week vernalization class it is evident that 1 week of natural day already results in retardation, while as the vernalization has been more sub-optimal the natural-day treatments should be longer in order to obtain the optimal acceleration for that treatment. With 6 weeks of cold this is reached after 1 week of natural day,
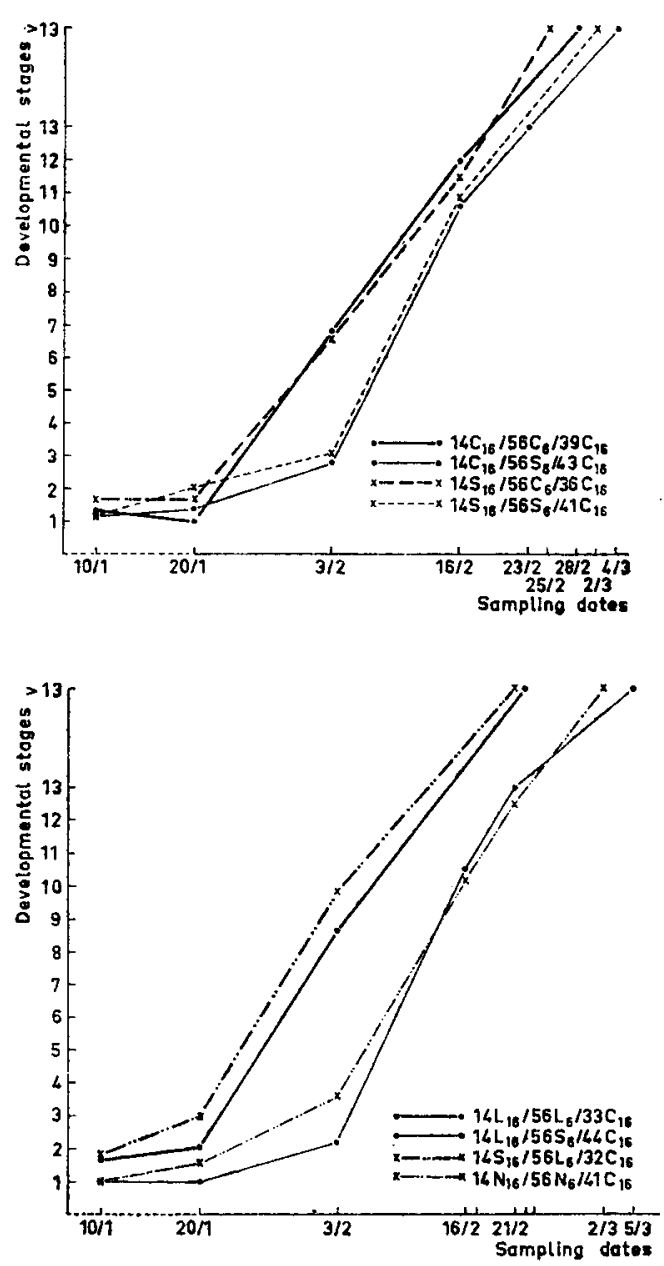

Neth. J. agric. Sci., Vol. 12 (1964) No. 2 (May)
FIG. 11

Development curves in the 8week vernalization class with additional fluorescent illumination

Frg. 12

Development curves in the 8week vernalization class with additional incandescent illumination 
with 4 weeks of cold after 3 weeks and with 2 weeks of vernalization after 4 weeks of natural day. The series can be extended by PuRvis and GREGory's observation (1937) that non-vernalized winter rye reaches the optimum after a natural-day interval of 6 weeks.

\subsection{Results in 1961}

Applying natural day in the previous investigations probably has not been quite correct as the varying daylength in the period from sowing to ear emergence, undoubtedly, will have influenced the results. Due to differences in the sowing dates, in order to put all occasions in the post-treatment at the same time, not all natural-day periods in the pre-treatment have been the same for each vernalization class. For the treatments sown earliest (October) daylength may be put at $\pm 101 / 2$ hours, while it amounts to 8 hours in those that had short cold treatments. In 1961 therefore daylength was adjusted to 8 hours by screening (short day $=S$ ) during the cold period as well as before and after.

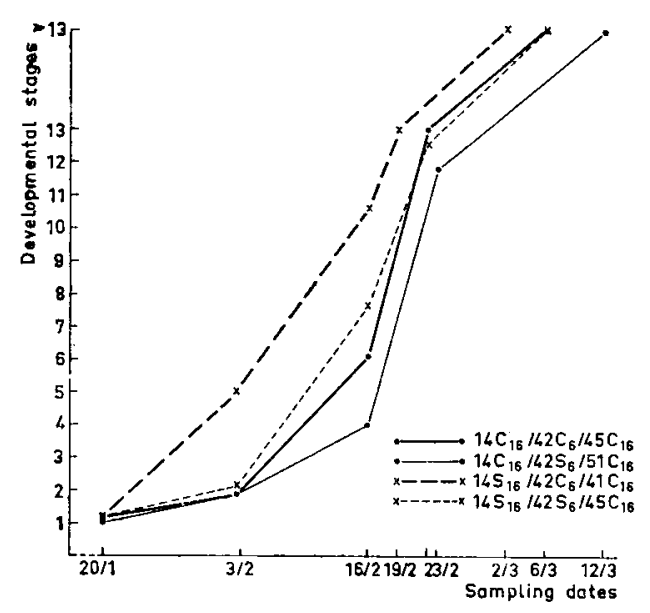

FIG. 13

Development curves in the 6week vernalization class

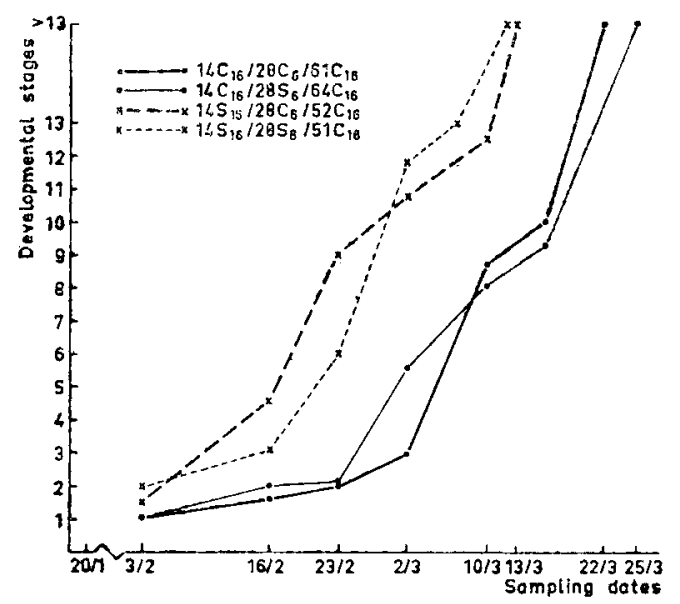

FIG. 14

Development curves in the 4week vernalization class 
Growth of the main stem in the various treatments was inferred from the dry weights of consecutive samples (FIG. 1-8). The differences in growth are not so evident as would have been the case had lengths been plotted. In the continuous-day treatments $14 \mathrm{C}_{16} / 56 \mathrm{C}_{6} / 39 \mathrm{C}_{16}$ and $14 \mathrm{~L}_{16} / 56 \mathrm{~L}_{6} / 33 \mathrm{C}_{16}$, receiving additional illumination with fluorescent tubes (C) and incandescent lamps (L) respectively (FIG. 3 and 4), the dry weights differ only slightly, but the differences in length were considerable. Yet the cases receiving short day in the pre-treatment and/or during vernalization obviously show a reduction in growth compared to those in continuous day.

Development, however, (FIG. 9-16) shows an undeniable advantage of short-day treatments over the relevant continuous-day treatments $\left(14 \mathrm{~S}_{16} / \ldots \mathrm{C}_{6} / \ldots \mathrm{C}_{16}\right.$ to $14 \mathrm{C}_{16} /$ $\ldots C_{6} / \ldots C_{16}$ and $14 S_{16} / \ldots S_{6} / \ldots C_{16}$ to $14 C_{16} / \ldots S_{6} / \ldots C_{16}$ ). The exception in $14 C_{16} /$ $84 \mathrm{C}_{6} / 28 \mathrm{C}_{16}$ (FIG. 9) is probably due to heterogeneity of the crop and in this case a few forward plants in sampling may have raised the average too high.

Curiously enough the development curves of continuous day and natural day intercross during the post-treatment where all treatments receive the same temperature
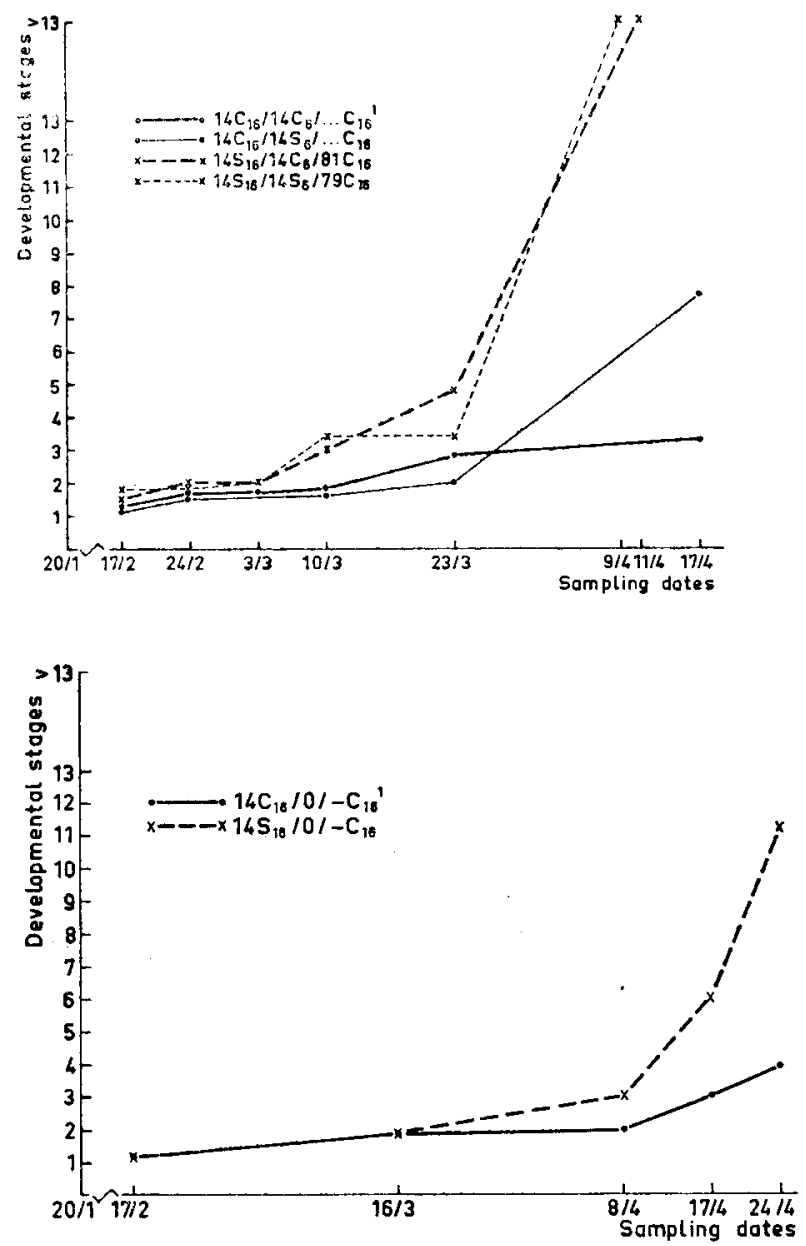

FIG. 15

Development curves in the 2week vernalization class

Fig. 16

Development curves of unvernalized winter rye 
and daylength. Presumably, this is associated with the 2 nd growth depression due to the period of ultimate spikelet number, as reflected in the FIG. on p. 143. Very likely, the short-day treatments will reach this stage earlier and due to the ensuing growth reduction they will show a retardation in comparison with the continuous-day treatments. Later on the reverse will occur, when the continuous-day treatments reach this stage, while the short-day treatments have already passed it. The advantage of $14 \mathrm{C}_{16}$ / $84 \mathrm{C}_{6} / 28 \mathrm{C}_{16}$ mentioned above may then also be explained by the 1 st growth depression at the end of the vegetative stage.

Thus it is obvious that various stages occur during plant development, each showing a different growth picture. It can be imagined that each difference in growth rhythm is associated to a difference in development rhythm. The results in the different samplings and in the heading may accordingly be considered as the resultants of all accelerations and retardations occurring up to that moment.

The influence of the kind of light used in additional illumination is evident from FIG. 11 and 12 , in which the treatments $14 \mathrm{~L}_{16} / 56 \mathrm{~L}_{6} / 33 \mathrm{C}_{16}$ and $14 \mathrm{~S}_{16} / 56 \mathrm{~L}_{6} / 32 \mathrm{C}_{16}$ show an accelerated development and earlier heading in comparison to $14 \mathrm{C}_{16} / 56 \mathrm{C}_{6} /$ $39 \mathrm{C}_{16}$ and $14 \mathrm{~S}_{16} / 56 \mathrm{C}_{6} / 36 \mathrm{C}_{16}$ respectively. Other treatments (not included in the FIG.) gave similar results, viz. $14 \mathrm{C}_{16} / 56 \mathrm{C}_{6} / 39 \mathrm{C}_{16}$ and $14 \mathrm{~L}_{16} / 56 \mathrm{~L}_{6} / 33 \mathrm{C}_{16}$ compared to $14 \mathrm{C}_{16} / 56 \mathrm{C}_{6} / 34 \mathrm{~L}_{16}$ and $14 \mathrm{~L}_{16} / 56 \mathrm{~L}_{6} / 28 \mathrm{~L}_{16}$ respectively. Additional illumination with incandescent lamps in the post-treatment promotes development by as much as 5 days in both cases.

In the treatments with rather short vernalization periods (FIG. 13-16) the development curves of $14 \mathrm{~S}_{16} / \ldots \mathrm{S}_{6} / \ldots \mathrm{C}_{16}$ relative to $14 \mathrm{C}_{16} / \ldots \mathrm{C}_{6} / \ldots \mathrm{C}_{16}$ appear to shift to the left. This is a result of the fact that the effect of a short-day period during the cold results in a greater acceleration because the retardation due to growth depressions is smaller.

One should note that in the 6-week vernalization class (FIG. 13), the developmental stages of the various treatments are similar at the beginning of the post-treatment, but at the next observation date $14 \mathrm{~S}_{16} / 42 \mathrm{C}_{6} / 41 \mathrm{C}_{16}$ is far ahead of $14 \mathrm{C}_{16} / 42 \mathrm{C}_{6} / 45 \mathrm{C}_{16}$. Thus the influence of short day during the pre-treatment shows not until much later as can also be seen in the 4-, 2- and 0-week vernalization classes.

The effect of short day then consists of a direct component, i.e. retardation correlated with growth inhibition, and an indirect component, showing as a postponed acceleration of shoot-apex differentiation.

\section{General discussion}

The experiments in 1958 and 1959 proved that the plants in the continuous-day treatments with additional illumination of incandescent light were larger than those receiving additional illumination of fluorescent tubes. This advantage in growth also caused earlier heading. It was assumed that also the short-day treatments, showing growth retardation relative to the corresponding continuous-day treatments, would show a delay in heading. Consequently, in those cases in which a short-day treatment shows an acceleration it is evident that besides a retardation also an acceleration must have occurred. This acceleration is due to more rapid differentiation of primordia, as has been observed by PuRvis (1934).

Accordingly, the influence of short day is two-fold. Slower growth and therefore a lower rate of development are due to a direct effect, the more rapid differentiation of primordia to an indirect effect, as this only shows after some time, when the plants 
have been placed in a favourable daylength, i.e. continuous day. Thus, besides cold vernalization there is also short-day vernalization. PURvis and GREGORY's observation (1937) that non-vernalized winter rye is accelerated by a short-day period of 6 weeks after sowing, should also be considered as a case of short-day vernalization.

The observation that prolonged short-day treatment results in retardation in heading is to be explained as follows. After a certain period of short-day the induction to an acceleration expressed in a more rapid differentiation of primordia will have reached its limit. In prolonged short-day conditions this limit is maintained, but the retardation due to the direct influence increases, so that the ultimate result will be a retardation.

The difference between the conceptions short-day induction and short-day vernalization, undoubtedly both a "photoperiodic after-effect or induction", should be clearly understood. Each affects a completely different group of plants, viz. short-day plants and long-day plants respectively. In short-day induction, short-day plants have to receive the required daylength (short day) for a certain number of days to enable the plant to flower in the next period of unfavourable daylength (long day). In short-day vernalization, however, a short-day treatment is applied to long-day plants, by which the plants are induced to flower early in the next period of favourable daylength (long day).

In plant vernalization cold and short day affect the plant at the same time, i.e., the cold affects the apical meristem at once, while the influence of short day begins when leaves have been formed. The optimal earliness, i.e. the minimum number of days a treatment needs up to heading, is actually reached by the combined effects of cold and of short day.

With seed vernalization, however, the cold effect dominates. After a sufficiently long cold period the conditions for optimal earliness may have already been reached. In that case a complementary short-day treatment will only induce retardation and acceleration is absent because the plant can no longer be accelerated. With suboptimal cold treatment, however, the short-day periods following cold treatment result in acceleration until the optimal earliness in that treatment has been reached. After this moment continuation of the short-day treatment will not increase the acceleration anymore, but the retardation by the direct effect will still increase. However, in plant vernalization as well as in seed vernalization also other influences besides retardation due to the direct effect and acceleration due to the indirect effect should be taken into account. They are autonomous retardations and are inherent to certain stages in plant development, for instance, growth depressions occurring at the end of the vegetative phase and at ultimate spikelet number.

\section{Conclusions}

1. Winter rye shows both cold and short-day requirement.

2. Like cold, short day has a direct and an indirect effect. The latter may simply be considered as short-day vernalization.

3. Winter rye is a long-day plant. The acceleration in non-vernalized winter rye by a short-day period of 6 weeks after sowing is due to short-day vernalization and not to short-day induction.

4. Cold vernalization and short-day vernalization are two different processes. Cold affects the apical meristem, while short day has influence when leaves have been formed. Under conditions in which both cold and short-day vernalization are applied (plant vernalization) each will independently influence the plant simultaneously. 
5. For additional illumination the choice of light is important. Light with a strong formative effect (incandescent bulbs) will give an advantage in growth in comparison to treatments illuminated by fluorescent tubes. This advantage in growth will lead to earlier heading.

\section{ACKNOWLEDGEMENT}

The author is indebted to drs. H. G. WitTenRood for his help in determining of the development stages and for the many hours of helpful discussion.

\section{LITER A T U RE}

BakHUizen, H. L. van DE SANDE

DenfFer, V. D.

Evans, L. T.

FeEKes, W.

GASSNER, G.

Gotr, M. B., F. G. GreGORY and O. N. PuRvis

Gregory, F. G., and O. N. Purvis

GREGORY, F. G.

HÄNSEL, $H$.

Hartman, Th. A.

KURTH, $H$.

Lang, A.

Maximov, N. A., and A. I. Pojarkova
1943 De ontwikkelingsgeschiedenis der tarweplant. Landbk. Tijdschr. 55, p. 533.

1947 Bloei en bloeihormonen in het bijzonder bij tarwe. I. (Flowering and flowering hormones especially in wheat. 1). Versl. Landbk. Onderz. No. 53.4. B, 145-212.

1939 Uber das Zusammenwirken von Keimstimmung und täglicher Belichtungsdauer auf die Entwicklung von Sinapis und Hordeum. Jahrb. f. wiss. Bot. LXXXVIII, 759-813.

1960 The influence of temperature on flowering in species of Lolium and in Poa pratensis. Journ. Agric. Sci. 54, 410-417.

1941 De tarwe en haar milieu. Versl. Techn. Tarwe Commissie. No. 17.

1918 Beiträge zur physiologischen Charakteristik sommer- und winterannueller Gewächse, insbesondere Getreidepflanzen. $\boldsymbol{Z}$. $f$. Bot. 10.

1955 Studies in vernalization of cereals XIII; Photoperiodic control of stages in flowering between initiation and ear formation in vernalized and unvernalized Petkus winter rye. Ann. of Bot. N.S. XIX, No. 73, 87-126.

1937 Studies in vernalization of cereals. I. A comparative study of vernalization of winter rye by low temperature and by short days. Ann. of Bot. 1: 4, 570—587.

1948 The control of flowering in plants. Symposia of the Society for experimental biology. Number II: Growth in relation to differentiation and morphogenesis. 75-103.

1951 Uber die Wirkung des Kurztages auf Zeit des Ährenschiebens und auf Ährchenzahl pro Ähre bei Petkus Winterroggen. Die Bodenkultur. Österr. Zentralorgan der Landwirtschaftwissenschaften und Ernährungsforschung. 5. Jahrgang. Heft 3, 305312.

1953 Vernalisation (Jarowisation, Kältestimmung). Zeitschr, f. Pfl. zücht. Band 32, Heft 3, 233-274.

1956 Jarowisatie-onderzoek in 1956. Meded. I.B.S. Wageningen. No. 20, 117-121.

1955 Die Jarowisation landwirtschaftlicher Kulturpflanzen. Die neue Brehm-Bücherei. A. Siemsen Verlag, Wittenberg Lutherstadt.

1952 Physiology of flowering. Ann. Review Plant Phys. III, 264300.

1925 Uber die physiologische Natur der Unterschiede zwischen Sommer- und Wintergetreide. Z. wiss. Bot. LXIV, 702-730. 
Maximov, N. A.

McKinney, H. H., and W. J. Sando

MCKINNEY, H. H.

Melchers, G., and A. LANG

PURvis, O. N.

Razumov, W. I., and T. Oleinikowa

THOMPSON, H. C.

Voss, J.

WiEbosch, W. A.

WitTenRoOD, H. G.

WHYTE, R. O.
1930 Physiological control of the length of the vegetative period. Abstracts 5th Intern. Bot. Congr. 1930.

1935 Earliness of sexual reproduction in wheat as influenced by temperature and light in relation to growth phases. Journ. of Agric. Research (FA 51).

1940 Vernalization and the growth-phase conception. Bot. Rev. 6, p. 25.

1948 Die Physiologie der Blütenbildung. Biol. Zentr. Blatt. fol. 67, No. 3, $4: 106-173$.

1934 An analysis of the influence of temperature during germination on the subsequent development of certain winter cereals and its relations to the effect of the length of day. Ann. of Bot. 48, p. 919.

1960 Der gegenwartige Stand der Arbeiten über Jarowisation. Sowjetwissenschaft; Naturwissenschaftliche Beiträge. Heft 12, 1264-1275.

1953 Vernalization of growing plants. Growth and differentiation in plants. Edited by Walter E. Loomis. p. 179-196.

1939 Weitere Untersuchungen über Entwicklungsbeschleunigung an Weizensorten, insbesondere an Winterweizen. Pflanzenbau. XV, $1-35,49-79$.

1950 Het veranderen van de vernalisatietoestand als hulpmiddel bij de plantenveredeling. (Changing the degree of vernalization as an aid to plant breeding). Meded. Dir. Tuinb. 13, 8: 593607.

1953 Het verloop van de vernalisatie van zes wintertarwerassen bij novemberzaai op het veld. Verslag Cilo 1952. 161-170.

1959 Correlatie tussen plant- en aargrootte ten tijde van de aaraanleg bij tarwe. (Correlation between size of plant and ear (ultimate number of spikelets) at ear initiation in wheat). Meded. I.B.S. No. 84, 135-146.

1948 History of research in vernalization. Vernalization and Photoperiodism. A symposium by A. E. MURNEEK and $\mathbf{R}$. $\mathbf{O}$. WHYTE, p. 1-37. 